Published in final edited form as:

Cancer Chemother Pharmacol. 2012 July ; 70(1): 49-56. doi:10.1007/s00280-012-1887-x.

\title{
Phase $\mathrm{I} / \mathrm{Il}$ trial of non-cytotoxic suramin in combination with weekly paclitaxel in metastatic breast cancer treated with prior taxanes
}

\author{
Maryam B. Lustberg, \\ Division of Medical Oncology, Department of Internal Medicine, The Ohio State University \\ Comprehensive Cancer Center, B421 Starling-Loving Hall, 320 West 10th Avenue, Columbus, \\ OH 43210-1240, USA maryam.lustberg@osumc.edu

\section{Shubham Pant,} \\ Division of Medical Oncology, Department of Internal Medicine, The Ohio State University \\ Comprehensive Cancer Center, B421 Starling-Loving Hall, 320 West 10th Avenue, Columbus, \\ $\mathrm{OH}$ 43210-1240, USA
}

\section{Amy S. Ruppert,}

Division of Medical Oncology, Department of Internal Medicine, The Ohio State University Comprehensive Cancer Center, B421 Starling-Loving Hall, 320 West 10th Avenue, Columbus, $\mathrm{OH}$ 43210-1240, USA

\section{Tong Shen,}

College of Pharmacy, The Ohio State University, Columbus, OH, USA

\section{Yong Wei,}

College of Pharmacy, The Ohio State University, Columbus, OH, USA

\section{Ling Chen,}

College of Pharmacy, The Ohio State University, Columbus, OH, USA

\section{Lisa Brenner,}

Division of Medical Oncology, Department of Internal Medicine, The Ohio State University Comprehensive Cancer Center, B421 Starling-Loving Hall, 320 West 10th Avenue, Columbus, $\mathrm{OH}$ 43210-1240, USA

\section{Donna Shiels,}

Division of Medical Oncology, Department of Internal Medicine, The Ohio State University Comprehensive Cancer Center, B421 Starling-Loving Hall, 320 West 10th Avenue, Columbus, OH 43210-1240, USA

\section{Rhonda R. Jensen,}

Division of Medical Oncology, Department of Internal Medicine, The Ohio State University Comprehensive Cancer Center, B421 Starling-Loving Hall, 320 West 10th Avenue, Columbus, $\mathrm{OH} 43210-1240$, USA

\section{Michael Berger,}

Department of Pharmacy, The Ohio State University Medical Center, Columbus, $\mathrm{OH}$, USA

\footnotetext{
(C) Springer-Verlag 2012

Correspondence to: Maryam B. Lustberg.

Electronic supplementary material The online version of this article (doi:10.1007/s00280-012-1887-x) contains supplementary material, which is available to authorized users.

Conflict of interest None.
} 
Ewa Mrozek,

Division of Medical Oncology, Department of Internal Medicine, The Ohio State University

Comprehensive Cancer Center, B421 Starling-Loving Hall, 320 West 10th Avenue, Columbus,

$\mathrm{OH}$ 43210-1240, USA

Bhuvaneswari Ramaswamy,

Division of Medical Oncology, Department of Internal Medicine, The Ohio State University Comprehensive Cancer Center, B421 Starling-Loving Hall, 320 West 10th Avenue, Columbus, $\mathrm{OH}$ 43210-1240, USA

Michael Grever,

Division of Medical Oncology, Department of Internal Medicine, The Ohio State University

Comprehensive Cancer Center, B421 Starling-Loving Hall, 320 West 10th Avenue, Columbus, $\mathrm{OH} 43210-1240$, USA

Jessie L. Au,

College of Pharmacy, The Ohio State University, Columbus, OH, USA

M. Guillaume Wientjes, and

College of Pharmacy, The Ohio State University, Columbus, OH, USA

Charles L. Shapiro

Division of Medical Oncology, Department of Internal Medicine, The Ohio State University

Comprehensive Cancer Center, B421 Starling-Loving Hall, 320 West 10th Avenue, Columbus, $\mathrm{OH}$ 43210-1240, USA

\section{Abstract}

Purpose-Suramin, a polysulfonated naphthylurea, inhibits the actions of polypeptide growth factors including acidic and basic fibroblast growth factors (aFGF and bFGF), which confer broad spectrum chemotherapy resistance. We hypothesized that suramin at non-cytotoxic doses in combination with weekly paclitaxel would be well tolerated and demonstrate anti-tumor activity.

Methods-Women with metastatic breast cancer who had been previously treated with a taxane in the adjuvant or metastatic setting were eligible. The primary objective of the phase I was to determine the dose of intravenous (IV) weekly suramin that resulted in plasma concentrations between 10 and $50 \mathrm{umol} / \mathrm{l}$ over $8-48 \mathrm{~h}$ (or the target range) in combination with IV $80 \mathrm{mg} / \mathrm{m}^{2}$ of weekly paclitaxel. The primary objective of the phase II trial was to determine the anti-tumor activity of the dosing regimen defined in phase I. Therapy was continued until disease progression or development of unacceptable toxicity.

Results-Thirty-one patients were enrolled (9: phase I; 22: phase II). In phase I, no dose-limiting toxicities were observed. Pharmacokinetics during the first cycle showed suramin concentrations within the target range for 21 of 24 weekly treatments $(88 \%)$. In phase II, the objective response rate (ORR) was $23 \%$ (95\% CI 8-45\%), the median progression-free survival was 3.4 months (95 $\%$ CI 2.1-4.9 months), and the median overall survival was 11.2 months (95\% CI 6.6-16.0 months).

Conclusions-Non-cytotoxic doses of suramin in combination with weekly paclitaxel were well tolerated. The efficacy was below the pre-specified criteria required to justify further investigation.

\section{Keywords}

Suramin; Paclitaxel; Metastatic; breast cancer; Phase I; Phase II 


\section{Introduction}

Resistance to chemotherapy is mediated by a number of factors including extracellular polypeptide growth factors such as acidic and basic fibroblast growth factors (aFGF and bFGF) [1]. Higher expression of bFGF is associated with resistance to the taxanes, anthracyclines, and anti-metabolites [2]. Suramin, a polysulfonated naphthylurea, inhibits multiple growth factors including aFGF, bFGF and at doses that are non-cytotoxic, suramin reverses FGF-induced drug resistance and enhances the anti-tumor activity of chemotherapies with diverse chemical structures and biological mechanisms in both cultured cells and in tumor-bearing animals $[1,3,4]$.

Paclitaxel, in the taxane family of tublin stabilizing agents, is one of the most active drugs in metastatic breast cancer. Based on preclinical evidence that non-cytotoxic suramin improves the efficacy of paclitaxel and enhances the in vivo antitumor activity of paclitaxel in human breast xenografts compared with paclitaxel alone $[4,5]$, we hypothesized that the combination of low non-cytotoxic doses suramin with weekly paclitaxel would be active and well tolerated in women with metastatic breast cancer. To test this hypothesis, a phase I/II trial of non-cytotoxic suramin in combination with paclitaxel in women with metastatic disease was undertaken in women who had previously received a taxane in either the adjuvant or metastatic setting.

The primary objective of the phase I trial was to determine the dose of IV weekly suramin in combination with IV $80 \mathrm{mg} / \mathrm{m}^{2}$ of weekly paclitaxel that would result in suramin plasma concentrations of $10-50 \mu \mathrm{M}$ for $8-48 \mathrm{~h}$; over this range, suramin is not cytotoxic and modulates the FGFs. The primary objective of the phase II trial was the objective response rate, and the secondary end points were toxicities of the combination, progression-free and overall survival, and evaluation of pretreatment plasma bFGF levels.

\section{Patients and methods}

\section{Eligibility}

Histologically confirmed stage IIIB or IV metastatic breast cancer and the following: age $\geq$ 18 years; eastern cooperative oncology group (ECOG) performance status of 0-2; prior paclitaxel or other taxanes (i.e., docetaxel) in either the adjuvant or metastatic setting; $\geq 3$ weeks from completion of prior chemotherapy, radiation therapy or surgery; white blood cell count $>3,000 / \mu \mathrm{l}$; absolute neutrophil count $\geq 1,000 / \mu \mathrm{l}$; platelets $\geq 100,000 / \mu \mathrm{l}$, and hemoglobin level $\otimes 9.0 \mathrm{~g} / \mathrm{dl}$; total serum bilirubin level $<1.5$ times institutional upper normal limits; aspartate amino transaminase and alanine amino transaminase $<2.5$ times upper normal limits; serum creatinine $<1.5 \mathrm{mg} / \mathrm{dl}$ or calculated creatinine clearance $\geq 50 \mathrm{ml} / \mathrm{min}$; no brain metastases or leptomeningeal disease; no history of hypersensitivity to cremophor EL; no other malignancy in the past 5 years with the exception of basal cell cancer or carcinoma in situ of the cervix; no other investigational drug use and not pregnant or lactating. In addition, patients were eligible for the phase II trial if they received $\_$prior chemotherapy regimens for stage IIIb or IV disease and had measurable disease according to RECIST criteria [6].

The treatment protocol and informed consent documents were approved by the Cancer Therapy Evaluation Program at the National Cancer Institute and the Institutional Review Boards at The James Cancer Hospital and Cleveland Clinic. Patients gave written informed consent according to the federal and institutional guidelines before treatment. 


\section{Study design, dosage, and dose modifications}

The phase I study was conducted in the James Cancer Hospital Clinical Treatment Unit, and the phase II trial was conducted in the outpatient settings at James Cancer Hospital and the Cleveland Clinic. Paclitaxel was administered at a dose of $80 \mathrm{mg} / \mathrm{m}^{2}$ IV on days $1,8,15$, and 21 of a 28-day treatment cycle in combination with suramin dose determined by a nomogram [7]. Patients continued to receive therapy until disease progression or development of unacceptable toxicity.

Suramin was supplied by the National Cancer Institute, division of cancer treatment and evaluation (CTEP), in sterile $600 \mathrm{mg} 10$-ml vials. The vials were reconstituted with sterile water, resulting in a $100 \mathrm{mg} / \mathrm{ml}$ solution. The desired dose was additionally diluted in $0.9 \%$ sodium chloride or $5 \%$ dextrose in water. Suramin was administered by IV infusion over 30 min, $4 \mathrm{~h}$ prior to IV $60 \mathrm{~min}$ paclitaxel infusion. The target dose was calculated to yield plasma concentrations between 10 and $50 \mu \mathrm{M}$ over approximately $8-48 \mathrm{~h}$.

Commercially available paclitaxel was obtained in $30 \mathrm{mg}(5 \mathrm{ml}), 100 \mathrm{mg}(16.7 \mathrm{ml})$, and 300 $\mathrm{mg}(50 \mathrm{ml})$ vials and was prepared according to the manufacturer's directions in glass or polyolefin containers diluted in $0.9 \%$ sodium chloride or $500-1,000 \mathrm{ml}$ of $5 \%$ dextrose. The paclitaxel was infused over $1 \mathrm{~h}$. Premedications given $30 \mathrm{~min}$ prior to the start of the paclitaxel infusion were $50 \mathrm{mg}$ IV of diphenhydramine and $20 \mathrm{mg}$ IV of famotidine; dexamethasone $20 \mathrm{mg}$ was administered orally at 12 and $6 \mathrm{~h}$ prior to the paclitaxel infusion.

In the phase I trial, dose adjustments were based on the pharmacokinetics of suramin and for dose-limiting toxicity. The goal was to achieve the target suramin plasma level of 10-50 $\mu \mathrm{M}$ in 5 of 6 patients, as long as no dose-limiting toxicity was observed in more than 1 of 6 patients. Dose-limiting toxicities during treatment cycle 1 were defined as follows: any grade 3 or higher non-hematologic toxicity or any grade 4 hematologic toxicity excluding asymptomatic grade 4 neutropenia (ANC < 500/ul) for durations less than 7 days. Toxicities were graded according to the National Cancer Institute Common Toxicity Criteria version 2.0. Additionally, failure to complete all planned treatment during cycle 1 for reasons other than disease progression or voluntary withdrawal was considered a dose-limiting toxicity.

In the phase II trial, paclitaxel was dose reduced from 80 to $70 \mathrm{mg} / \mathrm{m}^{2}$ for febrile neutropenia and for neutropenia lasting greater than 7 days. Neurotoxicity prompted dose reductions in suramin and paclitaxel. For grade 1, no dose reductions were permitted; for grade 2, suramin was administered at $75 \%$ and no dose reduction of paclitaxel; for grade 3, suramin $50 \%$ and paclitaxel reduced from 80 to $70 \mathrm{mg} / \mathrm{m}^{2}$; and for grade 4 , the treatment was discontinued. Treatment was discontinued if there was recurrence of grade 2 neuropathy or higher after dose reduction.

\section{Study assessments}

Pretreatment evaluations included a history and physical examination, ECOG performance status, complete blood count (CBC), serum chemistries, coagulation profile, urinalysis, electrocardiogram and radiological imaging with computed tomography (CT), and bone scans all within 4 weeks prior to study initiation. Women of childbearing potential had urine or serum pregnancy test prior to therapy initiation. During chemotherapy, evaluations included physical examination with performance status assessment on day 1 of treatment cycles; weekly laboratory studies included CBC with differential and serum chemistries; and imaging of the target lesions was completed every 2 cycles for women enrolled in the phase II. RECIST version 1.0 was used to define objective responses [6]. 


\section{Calculation of suramin doses}

The dose of suramin $(\mathrm{mg})$ was calculated, using a dosing nomogram (i.e., dose equals the product of "FACTOR" and the squared value of the body surface area of a patient) to yield the target concentration range of $10-50 \mu \mathrm{M}$ from 8 to $48 \mathrm{~h}$ (Supplemental Table 1). The value of FACTOR for the first dose was 125. The value of FACTOR for subsequent doses was calculated based on the time elapsed since the previous treatment. The first three patients enrolled on the study used an earlier version of the nomogram; the remaining patients in the phase I and II trial used the final version previously reported [7].

\section{Suramin pharmacokinetics}

Blood samples were obtained from the arm contralateral to the site of drug infusion and placed in heparinized tubes. For the assessment of suramin pharmacokinetics, different sampling schedules were used in the phase I and phase II trials. For patients in phase I, a total of 16 samples (pretreatment, and 0.16, 0.33, 0.5, 1, 1.5, 2, 3, 4.5, 5.5, 9, 12, 15, 24, 48, and $72 \mathrm{~h}$ after initiation of suramin infusion) were collected during the first and fourth weeks of cycle 1. For subsequent cycles, 3 samples were collected (pretreatment, 3 and $4.5 \mathrm{~h}$ after treatment initiation). For patients in phase II trial, a total of 6 samples were collected during the first and fourth weeks of cycle 1 (pretreatment, and 0.5, 3, 4.5, 5.5, and $6 \mathrm{~h}$ after treatment initiation), and 3 samples were collected in subsequent cycles (pretreatment, and 3 and $4.5 \mathrm{~h}$ after treatment initiation). Samples were analyzed for suramin concentrations using a previously described high-performance liquid chromatography method ${ }^{2}$ and for bFGF levels (see correlatives section).

Drug concentrations at these time points in the phase I patients were estimated by fitting a three-compartment open model with multiple dosing (WinNonlin, Pharsight, Mountain View, CA, USA) to the concentration-time profiles [7]. Suramin concentrations (actual measurements) were compared in patients on the phase I and II trials at the same time points (pretreatment, 0.5, 3, 4.5, and $5.5 \mathrm{~h}$ for the first and fourth weekly treatment in cycle 1, and pretreatment, 3 and $4.5 \mathrm{~h}$ for the first weekly treatment of the remaining cycles).

\section{Correlative studies for bFGF}

Pretreatment plasma bFGF concentrations were evaluated on all patients. All plasma samples were analyzed for bFGF concentrations using an Enzyme-Linked ImmunoSorbent Assay kit (Oncogene, Cambridge, MA, USA), following the manufacturer's instructions. The antibody was a murine monoclonal anti-bFGF antibody conjugated with horseradish peroxidase. The lower detection limit of the assay was $2.5 \mathrm{pg} / \mathrm{ml}$.

\section{Statistical methods and analysis}

The primary end point of the phase I trial was to determine the dosing nomogram yielding the target suramin plasma level of $10-50 \mu \mathrm{M}$ in 5 of 6 patients, as long as dose-limiting toxicity was not seen in more than 1 of 6 patients. The primary end point of the phase II trial was the overall response rate. With 28 patients in the phase II portion, there was $83 \%$ power to detect an improvement in overall response from 30 to $50 \%$ with a Type I error rate of 10 $\%$. Thus, to warrant further study, this study required at least $12(43 \%)$ observed responses. The overall response rate and the $95 \%$ exact Clopper-Pearson confidence interval were calculated. Progression-free (PFS) and overall survival (OS) estimates were calculated using the Kaplan-Meier method. PFS was measured from the date on-study until the date of progression or death, whichever came first, censoring those alive and progression-free. There were no DLTs in Phase I. Seven patients ( 3 in phase I and 4 in phase II) went offstudy due to toxicity and received other types of chemotherapy; these were censored for PFS at the date off-study. OS was defined as the date from on-study until the date of death, 
censoring those alive at last follow-up. Pretreatment bFGF levels and the relationship to response were tested in the phase II cohort using the nonparametric Kruskal-Wallace test.

\section{Results \\ Patient characteristics}

Between April 2003 and June 2007, 31 women with metastatic breast cancer were enrolled. Baseline patient characteristics are described in Table 1. Nine patients were enrolled in phase I and 22 in phase II. The median age was 56 (range 35-73) and median ECOG was 0 (range 0-2). All patients had received prior taxanes, either in the adjuvant (26\%) or in metastatic setting $(52 \%)$, or in both $(23 \%)$. Fourteen $(64 \%)$ patients in the phase II trial had received a prior taxane in the metastatic setting. Of these, 2 had discontinued taxane treatment for toxicity and 12 for progressive disease. The majority of patients on the phase II study had received one (48\%) or two (32\%) prior chemotherapy regimens.

\section{Treatment}

Nine patients completed 22 treatment cycles in the phase I study and 21 patients completed 63 cycles in the phase II study. One patient started but did not complete the first cycle of treatment due to progressive disease. The median number of cycles that was completed was 2 (range 1-8 cycles). As illustrated in Fig. 1, all 9 patients in Phase I trial received the same suramin loading dose, which yielded a peak concentration of about $90 \mu \mathrm{M}$ at the end of the 30 -min infusion, declining to about $50 \mu \mathrm{M}$ at $4.5-5.5 \mathrm{~h}$, and subsequently to about $15 \mu \mathrm{M}$ at $48 \mathrm{~h}$. Doses for subsequent treatments (administered 7 days after the previous treatment) were calculated with a FACTOR value of 45 for the first 3 patients on the phase I trial and a FACTOR value of 39 for the remaining 6 patients (using the final nomogram). Pharmacokinetic studies during the first cycle of these patients (24 treatments) showed suramin concentrations within the target range of $10-50 \mu \mathrm{M}$ over $8-48 \mathrm{~h}$ in 21 treatments $(88 \%)$. The remaining 3 treatments were received by a single patient, exhibiting $48 \mathrm{~h}$ concentrations of $4-5 \mu \mathrm{M}$. This result is similar to the results of other suramin trials, where the target concentrations were achieved in $\searrow 90 \%$ of patients [7-10].

A total of 22 phase II patients were treated on the final dosing nomogram. Their measured plasma concentrations at 5 time points (i.e., pretreatment, $0.5,3,4.5$, and $5.5 \mathrm{~h}$ ) were comparable to the concentrations in the 6 phase I patients treated on the same nomogram.

\section{Toxicities}

All treatment-related adverse events are reported in Table 2. Therewere no dose-limiting toxicities in the phase I study.The majority of treatment-related toxicities were grade 1 and 2. Grade 3 and 4 neutropenia occurred in 10 and $3 \%$ of patients, respectively. The most common grade 3 and 4 non-hematologic toxicity was fatigue (19\%). Only $2(6 \%)$ developed grade 3 neuropathy ( 1 sensory and 1 motor). Both had prior taxane exposure. Although there were no deaths attributable to toxicity, one patient subsequently died within 30 days of coming off trial for progressive disease due to complications of Acute Respiratory Distress Syndrome (ARDS).

The toxicities that led to dose reduction or dose delays in paclitaxel and/or suramin included grade 3 fatigue $(n=2)$, grade 2 neuropathy $(n=5)$, neutropenia $(n=1)$, and pneumonia $(n=$ 1). Seven (23\%) patients (phase I: $n=3$; phase II: $n=4$ ) discontinued treatment due to toxicities, with five discontinuing due to grade 3 or recurrent grade 2 neuropathy. 


\section{Efficacy}

Efficacy results for the Phase II portion are shown in Table 3. Twenty-two phase II patients were evaluated in the intent-to-treat analysis. Over half $(55 \%)$ of the phase II patients had previously progressed within 6 months while being treated with a taxane for metastatic disease. These patients were considered taxane-refractory. There were no complete responses; 5 patients had partial response (PR) and the overall response rate was $23 \%$ (95\% CI 8-45\%). Two of the patients with PR progressed during cycle 3 . A total of $9(41 \%)$ patients had stable disease (SD), with 7 patients (32\%) SD for a duration of at least 8 weeks. Of the taxane-refractory patients, two (17\%) achieved a PR and six others $(50 \%)$ achieved SD. Response rates in patients with triple-negative breast cancer were 2 PR (25 $\%), 1 \mathrm{SD}(13 \%)$, and $5 \mathrm{PD}(63 \%)$. Response rates in patients with endocrine positive breast cancer were 3 PR $(21 \%), 8$ SD (57 \%), and 3 PD (21\%). Response rates between the two groups were not significantly different $(p=0.11)$. As shown in Fig. 2, the median PFS for all treated patients in the phase II study was 3.4 months (95\% CI 2.1-4.9 months) and the median OS was 11.2 months (95\% CI 6.6-16.0 months).

\section{bFGF correlative studies}

Plasma levels of bFGF were measured prior to beginning suramin treatment in all 22 patients on the phase II study. The median level was $7.1 \mathrm{pg} / \mathrm{ml}$ (range 0.0-23.5). Two patients did not express any pretreatment bFGF levels. There was no association between baseline bFGF levels and response ( $p=0.35$; data not shown).

\section{Discussion}

Suramin at therapeutic concentrations impacts a number of cancer-related pathways including inhibition of angiogenesis, phosphorylation of protein kinase $\mathrm{C}$, and metabolism of glycolsaminoglycan [11-13]. Clinical trials using suramin at concentrations of 100-300 $\mu \mathrm{M}$ as a single agent [14-16] or in combination with cytotoxic agents [17, 18] demonstrated significant toxicities with only modest efficacy. In breast cancer, suramin as a single agent at concentrations of $140 \mu \mathrm{M}$ was associated with significant toxicity [19]. Based on these results, the U.S. Food and Drug Administration disapproved the use of suramin at therapeutic concentrations.

In contrast to the high concentrations of suramin needed for anti-tumor activity, much lower, non-cytotoxic doses of suramin ranging between 10 and $50 \mu \mathrm{M}$ inhibit FGFs. Suramin at these low concentrations enhances the antitumor effects of various chemotherapeutic agents in a variety of tumor cell lines [1] and in several animal models including prostate [3], lung [20], bladder [21], and breast [4]. In breast cancer models, low-dose suramin enhanced the activity of paclitaxel in breast cancer xenografts with lung metastases compared with paclitaxel alone [4].

These promising preclinical results led to several early phase clinical trials evaluating noncytotoxic suramin in combination with standard chemotherapy drugs in solid tumors $[9,10$, $22,23]$. Suramin was well tolerated when combined with carboplatin and paclitaxel in patients with advanced stage non-small cell lung carcinomas [22]. Comparing the response rates in chemotherapy naive and pretreated non-small cell lung cancer, patients did not show evidence of an apparent enhancement of response rates in patients who were chemotherapy naive [9]. A phase I study of suramin in combination with docetaxel and gemcitabine therapy showed tolerability and encouraging anti-tumor activity [23], and randomized phase II trials are ongoing or being initiated in chemotherapy naïve and pretreated non-small lung cancer patients [24]. 
In this phase I/II trial, non-cytotoxic suramin in combination with weekly paclitaxel was well tolerated. One of the limitations of the trial was that the phase II enrollment did not meet its goal of twenty-eight patients. Trial enrollment was terminated early due to withdrawal of drug sponsorship by CTEP when only 22 patients were enrolled. Other limitations of this trial include the small sample size and heterogeneity of patient population in terms of prior treatment regimens. The objective response rate (ORR) attained in the 22 enrolled patients $(23 \%)$ did not provide enough evidence to reject the null hypothesis that the true response rate is less than or equal to $30 \%$.

When this trial was initially designed, there was limited data in response rates in a previously treated metastatic population. Single-agent paclitaxel in ECOG 2100 as first-line metastatic therapy had ORR of 21-22\% with no difference in responses in patients with or without taxanes therapy in the adjuvant setting $[25,26]$. Trials with single-agent capecitabine in taxane-pretreated metastatic breast cancer women yielded ORR ranging 20$27 \%[20,27]$. In a recent trial, ORR in heavily pre-treated, taxane-refractory patients treated with single-agent ixabepilone was only $12 \%$ [28]. The patients in the ixabipilone trial had received prior anthracycline, and docetaxel or paclitaxel-based chemotherapy as their most recent chemotherapy, and experienced progression of disease on taxane therapy within 4 months of their last dose.

The definition of taxane resistance varies across metastatic trials. In our study, 12 (55\%) phase II patients had previously experienced disease progression within 6 months during a prior taxane therapy ( 9 taxotere, 1 abraxane, 2 paclitaxel) for metastatic disease. Of these, 2 $(17 \%)$ achieved a PR. In addition, six $(50 \%)$ patients achieved disease stability. These numbers, although small, may be clinically relevant since patients with taxane-refractory MBC have limited treatment options. However, the overall median number of cycles was 2 and the short median progression- free survival of 3.4 months highlights the limited efficacy seen with this combination in this population. Table 4 summarizes response rates from several studies with paclitaxel in the metastatic setting. Note that it is difficult to draw comparisons across these studies given differences in prior taxane exposure and prior lines of therapy.

There was no correlation between pretreatment bFGF levels with response. The relatively small sample size may have limited the power to detect a significant correlation between serum FGF levels and response rates or toxicities. Intra-tumoral bFGF levels were not assessed because a method of assaying for them was developed after the trial closed [29].

Other biomarkers of taxane resistance are currently under investigation. Tumors that overexpress the microtubule associated protein tau are less sensitive to taxanes [30,31]. Several other factors may be important in taxanes resistance pathways including class III $\beta$ tublins [32], and gene polymorphisms in ABCB1 [33] and CYP1B1 [34]. Additional studies are needed before these biomarkers can be incorporated into clinical decision making.

In conclusion, non-cytotoxic suramin in combination with weekly paclitaxel was a welltolerated combination in patients with MBC previously treated with taxanes. The efficacy of suramin in combination with paclitaxel was below the pre-specified criteria required to justify further investigation.

\section{Acknowledgments}

Supported by 3 P30 CA016058-33S2 Avon Foundation OSU Comprehensive Cancer Center Supplement and the K12 CA133250, Translational Training Grant in Expiremental Therapeutics. Au and Wientjes have been awarded patents on the use of suramin as a chemosensitizer. 


\section{References}

1. Song S, Wientjes MG, Gan Y, Au JL. Fibroblast growth factors: an epigenetic mechanism of broad spectrum resistance to anticancer drugs. Proc Natl Acad Sci USA. 2000; 97(15):8658-8663. [PubMed: 10890892]

2. Gan Y, Wientjes MG, Au JL. Expression of basic fibroblast growth factor correlates with resistance to paclitaxel in human patient tumors. Pharm Res. 2006; 23(6):1324-1331. [PubMed: 16741658]

3. Zhang Y, Song S, Yang F, Au JL, Wientjes MG. Nontoxic doses of suramin enhance activity of doxorubicin in prostate tumors. J Pharmacol Exp Ther. 2001; 299(2):426-433. [PubMed: 11602651]

4. Song S, Yu B, Wei Y, Wientjes MG, Au JL. Low-dose suramin enhanced paclitaxel activity in chemotherapy-naive and paclitaxel-pretreated human breast xenograft tumors. Clin Cancer Res. 2004; 10(18 Pt 1):6058-6065. [PubMed: 15447990]

5. Song S, Wientjes MG, Walsh C, Au JL. Nontoxic doses of suramin enhance activity of paclitaxel against lung metastases. Cancer Res. 2001; 61(16):6145-6150. [PubMed: 11507065]

6. Therasse P, Arbuck SG, Eisenhauer EA, Wanders J, Kaplan RS, Rubinstein L, Verweij J, Van Glabbeke M, van Oosterom AT, Christian MC, Gwyther SG. New guidelines to evaluate the response to treatment in solid tumors. European organization for research and treatment of cancer, national cancer institute of the United States, national cancer institute of Canada. J Natl Cancer Inst. 2000; 92(3):205-216. [PubMed: 10655437]

7. Chen D, Song SH, Wientjes MG, Yeh TK, Zhao L, Villalona-Calero M, Otterson GA, Jensen R, Grever M, Murgo AJ, Au JL. Nontoxic suramin as a chemosensitizer in patients: dosing nomogram development. Pharm Res. 2006; 23(6):1265-1274. [PubMed: 16715360]

8. Villalona-Calero MA, Blum JL, Jones SE, Diab S, Elledge R, Khoury P, Von Hoff D, Kraynak M, Moczygemba J, Kromelis P, Griffin T, Rowinsky EK. A phase I and pharmacologic study of capecitabine and paclitaxel in breast cancer patients. Ann Oncol. 2001; 12(5):605-614. [PubMed: 11432617]

9. Villalona-Calero MA, Otterson GA, Wientjes MG, Weber F, Bekaii-Saab T, Young D, Murgo AJ, Jensen R, Yeh TK, Wei Y, Zhang Y, Eng C, Grever M, Au JL. Noncytotoxic suramin as a chemosensitizer in patients with advanced non-small-cell lung cancer: a phase II study. Ann Oncol. 2008; 19(11):1903-1909. [PubMed: 18632723]

10. George S, Dreicer R, Au JJ, Shen T, Rini BI, Roman S, Cooney MM, Mekhail T, Elson P, Wientjes GM, Ganapathi R, Bukowski RM. Phase I/II trial of 5-fluorouracil and a noncytotoxic dose level of suramin in patients with metastatic renal cell carcinoma. Clin Genitourin Cancer. 2008; 6(2):79-85. [PubMed: 18824429]

11. Eisenberger MA, Reyno LM. Suramin. Cancer Treat Rev. 1994; 20(3):259-273. [PubMed: 8020006]

12. Stein CA. Suramin: a novel antineoplastic agent with multiple potential mechanisms of action. Cancer Res. 1993; 53(10 Suppl):2239-2248. [PubMed: 8485709]

13. Waltenberger J, Mayr U, Frank H, Hombach V. Suramin is a potent inhibitor of vascular endothelial growth factor. A contribution to the molecular basis of its antiangiogenic action. J Mol Cell Cardiol. 1996; 28(7):1523-1529. [PubMed: 8841939]

14. Bowden CJ, Figg WD, Dawson NA, Sartor O, Bitton RJ, Weinberger MS, Headlee D, Reed E, Myers CE, Cooper MR. A phase I/II study of continuous infusion suramin in patients with hormone-refractory prostate cancer: toxicity and response. Cancer Chemother Pharmacol. 1996; 39(1-2):1-8. [PubMed: 8995493]

15. Dreicer R, Smith DC, Williams RD, See WA. Phase II trial of suramin in patients with metastatic renal cell carcinoma. Invest New Drugs. 1999; 17(2):183-186. [PubMed: 10638490]

16. Falcone A, Pfanner E, Cianci C, Danesi R, Brunetti I, Del Tacca M, Conte PF. Suramin in patients with metastatic colorectal cancer pretreated with fluoropyrimidine-based chemotherapy. A phase II study. Cancer. 1995; 75(2):440-443. [PubMed: 7812913]

17. Falcone A, Pfanner E, Brunetti I, Allegrini G, Lencioni M, Galli C, Masi G, Danesi R, Antonuzzo A, Del Tacca M, Conte PF. Suramin in combination with 5-fluorouracil (5-FU) and leucovorin 
$(\mathrm{LV})$ in metastatic colorectal cancer patients resistant to 5-FU+LV-based chemotherapy. Tumori. 1998; 84(6):666-668. [PubMed: 10080673]

18. Falcone A, Antonuzzo A, Danesi R, Allegrini G, Monica L, Pfanner E, Masi G, Ricci S, Del Tacca M, Conte P. Suramin in combination with weekly epirubicin for patients with advanced hormonerefractory prostate carcinoma. Cancer. 1999; 86(3):470-476. [PubMed: 10430255]

19. Mirza MR, Jakobsen E, Pfeiffer P, Lindebjerg-Clasen B, Bergh J, Rose C. Suramin in non-small cell lung cancer and advanced breast cancer. Two parallel phase II studies. Acta Oncol. 1997; 36(2):171-174. [PubMed: 9140434]

20. Blum JL, Dees EC, Chacko A, Doane L, Ethirajan S, Hopkins J, McMahon R, Merten S, Negron A, Neubauer M, Ilegbodu D, Boehm KA, Asmar L, O'Shaughnessy JA. Phase II trial of capecitabine and weekly paclitaxel as first-line therapy for metastatic breast cancer. J Clin Oncol. 2006; 24(27):4384-4390. [PubMed: 16926223]

21. Xin Y, Lyness G, Chen D, Song S, Wientjes MG, Au JL. Low dose suramin as a chemosensitizer of bladder cancer to mitomycin C. J Urol. 2005; 174(1):322-327. [PubMed: 15947683]

22. Villalona-Calero MA, Wientjes MG, Otterson GA, Kanter S, Young D, Murgo AJ, Fischer B, DeHoff C, Chen D, Yeh TK, Song S, Grever M, Au JL. Phase I study of low-dose suramin as a chemosensitizer in patients with advanced non-small cell lung cancer. Clin Cancer Res. 2003; 9(9):3303-3311. [PubMed: 12960116]

23. Cristofanilli M, Broglio KR, Guarneri V, Jackson S, Fritsehe HA, Islam R, Dawood S, Reuben JM, Kau SW, Lara JM, Krishnamurthy S, Ueno NT, Hortobagyi GN, Valero V. Circulating tumor cells in metastatic breast cancer: biologic staging beyond tumor burden. Clin Breast Cancer. 2007; 7(6): 471-479. [PubMed: 17386124]

24. www.clinicaltrial.gov

25. Miller K, Wang M, Gralow J, Dickler M, Cobleigh M, Perez EA, Shenkier T, Cella D, Davidson NE. Paclitaxel plus bev-acizumab versus paclitaxel alone for metastatic breast cancer. N Engl J Med. 2007; 357(26):2666-2676. [PubMed: 18160686]

26. Gray R, Bhattacharya S, Bowden C, Miller K, Comis RL. Independent review of E2100: a phase III trial of bevacizumab plus paclitaxel versus paclitaxel in women with metastatic breast cancer. $\mathbf{J}$ Clin Oncol. 2009; 27(30):4966-4972. [PubMed: 19720913]

27. Blum JL, Dees EC, Vukelja SJ, Amare M, Gill DP, McMahon RT, Ilegbodu D, Asmar L, O'Shaughnessy JA. Phase II trial of capecitabine and weekly paclitaxel in patients with metastatic breast cancer previously treated with every-3-week taxane therapy. Clin Breast Cancer. 2007; 7(6): 465-470. [PubMed: 17386123]

28. Thomas E, Tabernero J, Fornier M, Conte P, Fumoleau P, Lluch A, Vahdat LT, Bunnell CA, Burris HA, Viens P, Baselga J, Rivera E, Guarneri V, Poulart V, Klimovsky J, Lebwohl D, Martin M. Phase II clinical trial of ixabepilone (BMS-247550), an epothilone B analog, in patients with taxane-resistant metastatic breast cancer. J Clin Oncol. 2007; 25(23):3399-3406. [PubMed: 17606975]

29. Walsh CT, Wei Y, Wientjes MG, Au JL. Quantitative image analysis of intra-tumoral bFGF level as a molecular marker of paclitaxel resistance. J Transl Med. 2008; 6:4. [PubMed: 18205918]

30. Rouzier R, Perou CM, Symmans WF, Ibrahim N, Cristofanilli M, Anderson K, Hess KR, Stec J, Ayers M, Wagner P, Morandi P, Fan C, Rabiul I, Ross JS, Hortobagyi GN, Pusztai L. Breast cancer molecular subtypes respond differently to preoperative chemotherapy. Clin Cancer Res. 2005; 11(16):5678-5685. [PubMed: 16115903]

31. Andre F, Hatzis C, Anderson K, Sotiriou C, Mazouni C, Mejia J, Wang B, Hortobagyi GN, Symmans WF, Pusztai L. Microtubule-associated protein-tau is a bifunctional predictor of endocrine sensitivity and chemotherapy resistance in estrogen receptor-positive breast cancer. Clin Cancer Res. 2007; 13(7):2061-2067. [PubMed: 17404087]

32. Stengel C, Newman SP, Leese MP, Potter BV, Reed MJ, Purohit A. Class III beta-tubulin expression and in vitro resistance to microtubule targeting agents. Br J Cancer. 2010; 102(2):316324. [PubMed: 20029418]

33. Chang H, Rha SY, Jeung HC, Im CK, Ahn JB, Kwon WS, Yoo NC, Roh JK, Chung HC. Association of the ABCB1 gene polymorphisms $2677 \mathrm{G}>\mathrm{T} / \mathrm{A}$ and $3435 \mathrm{C}>\mathrm{T}$ with clinical 
outcomes of paclitaxel monotherapy in metastatic breast cancer patients. Ann Oncol. 2009; 20(2): 272-277. [PubMed: 18836089]

34. Marsh S, Somlo G, Li X, Frankel P, King CR, Shannon WD, McLeod HL, Synold TW. Pharmacogenetic analysis of paclitaxel transport and metabolism genes in breast cancer. Pharmacogenomics J. 2007; 7(5):362-365. [PubMed: 17224914]

35. Seidman AD, Hudis CA, Albanell J, Tong W, Tepler I, Currie V, Moynahan ME, Theodoulou M, Gollub M, Baselga J, Norton L. Dose-dense therapy with weekly 1-hour paclitaxel infusions in the treatment of metastatic breast cancer. J Clin Oncol. 1998; 16(10):3353-3361. [PubMed: 9779712]

36. Perez EA, Vogel CL, Irwin DH, Kirshner JJ, Patel R. Multicenter phase II trial of weekly paclitaxel in women with metastatic breast cancer. J Clin Oncol. 2001; 19(22):4216-4223. [PubMed: 11709565]

37. Lombardi D, Crivellari D, Scuderi C, Magri MD, Spazzapan S, Sorio R, Di Lauro V, Scalone S, Veronesi A. Long-term, weekly one-hour infusion of paclitaxel in patients with metastatic breast cancer: a phase II monoinstitutional study. Tumori. 2004; 90(3):285-288. [PubMed: 15315306]

38. Seidman AD, Berry D, Cirrincione C, Harris L, Muss H, Marcom PK, Gipson G, Burstein H, Lake D, Shapiro CL, Ungaro P, Norton L, Winer E, Hudis C. Randomized phase III trial of weekly compared with every-3-weeks paclitaxel for metastatic breast cancer, with trastuzumab for all HER-2 overexpressors and random assignment to trastuzumab or not in HER-2 nonoverexpressors: final results of cancer and Leukemia group B protocol 9840. J Clin Oncol. 2008; 26(10):1642-1649. [PubMed: 18375893] 


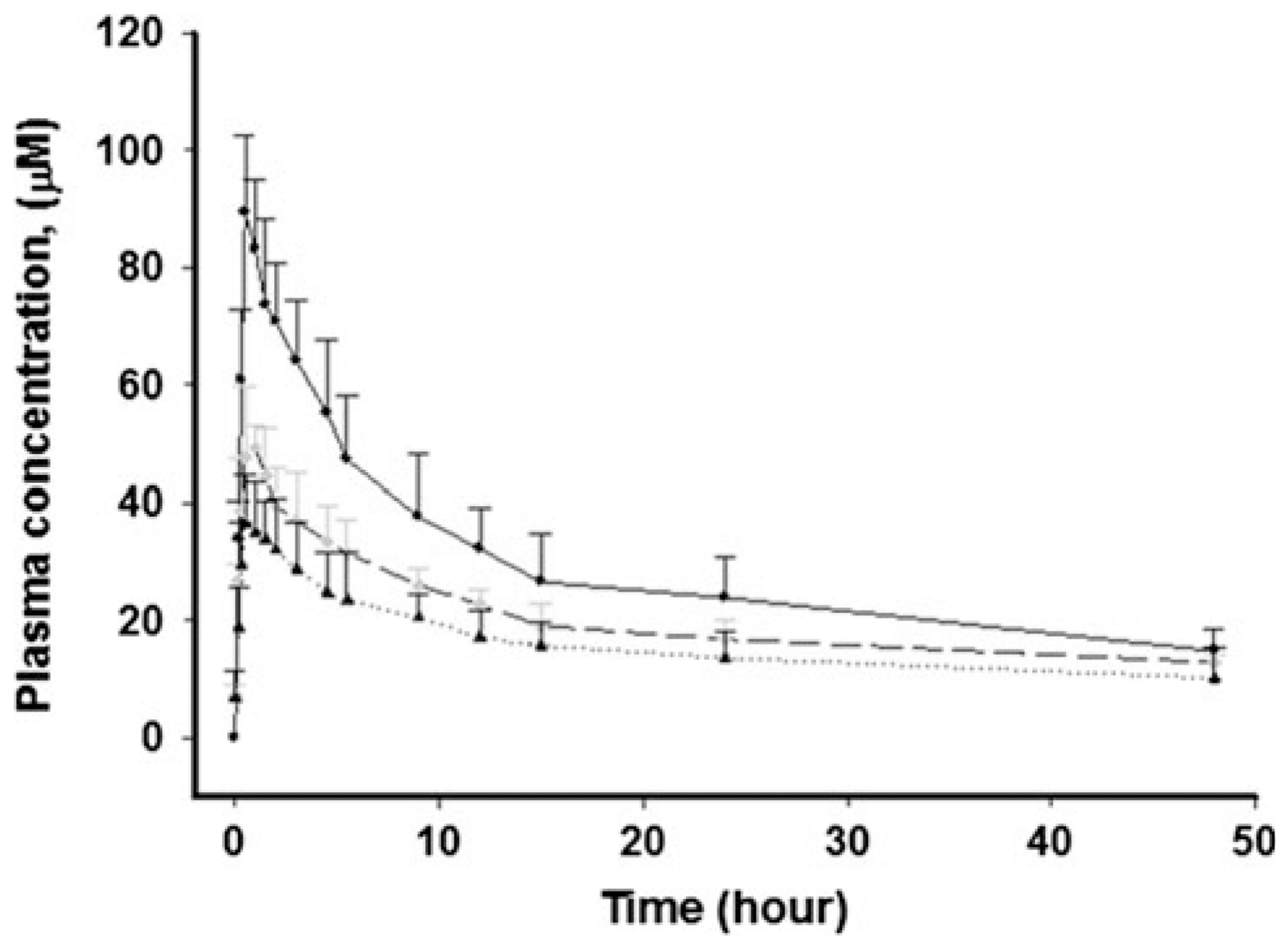

Fig. 1.

Suramin pharmacokinetics were evaluated to ensure that the suramin target plasma concentration range of $10-50 \mu \mathrm{M}$ was maintained over 8-48 h. Three cohorts of 3 patients each were enrolled in the phase I trial. From top to bottom: solid line, 1st treatment for all patients $(n=9)$; dashed line, 4th treatment of cohort $1(n=3)$; dotted line, 4th treatment of cohorts 2 and $3(n=6)$. All 9 patients received a first-cycle suramin dose (in $\mathrm{mg}$ ) of 125 times the square of the body surface area $\left(\mathrm{BSA}^{2}\right)$. In order to maintain target plasma concentrations, the first cohort received subsequent doses of $45 \times \mathrm{BSA}^{2}$, while cohorts 2 and 3 received $39 \times \mathrm{BSA}^{2}$ 


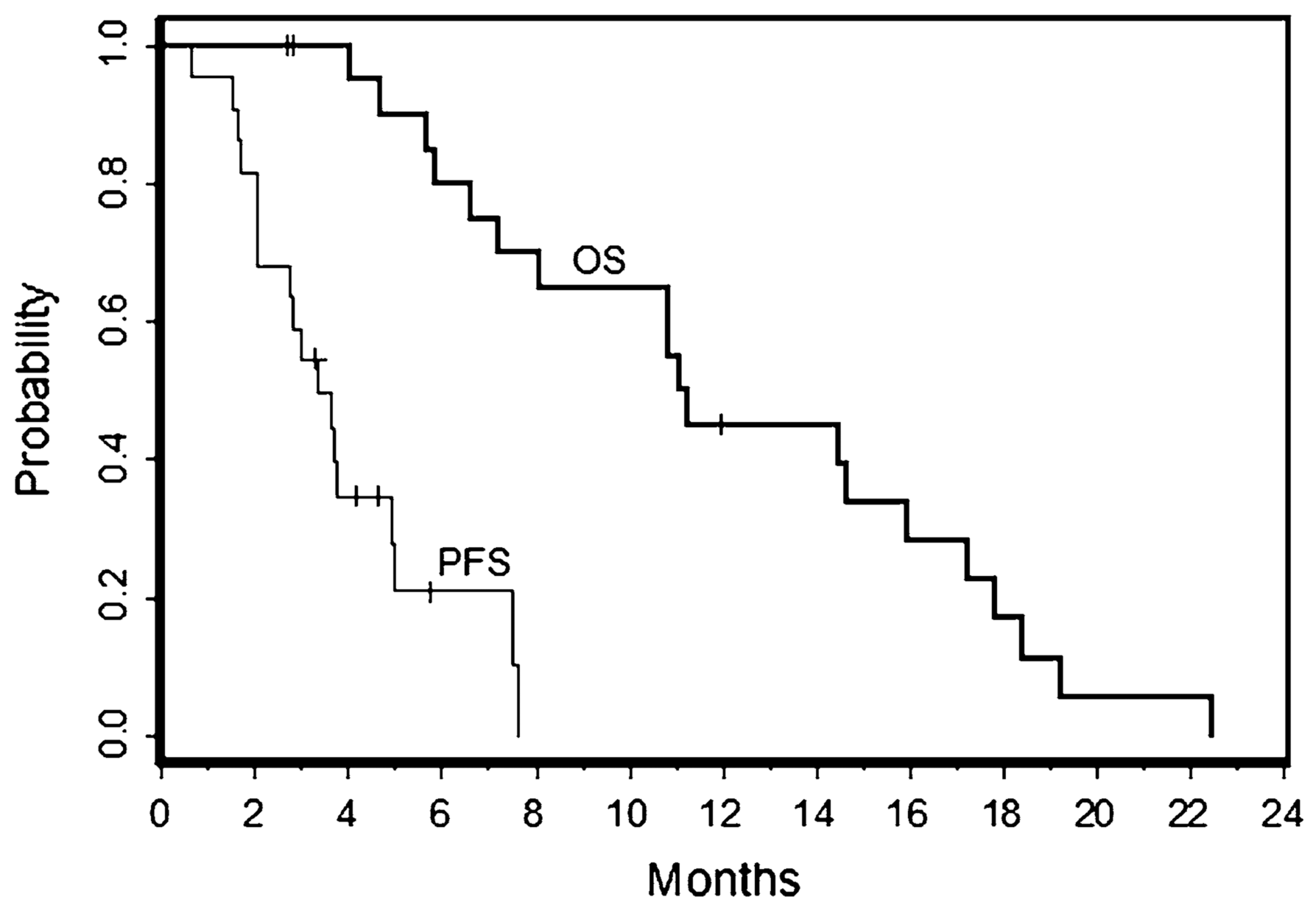

Fig. 2.

In the 22 patients enrolled in the phase II portion, median PFS was 3.4 months (95\% CI 2.1-4.9) and median OS was 11.2 months (6.6-16.0 months) 
Table 1

Patient characteristics

\begin{tabular}{|c|c|c|c|}
\hline Characteristics & $\begin{array}{l}\text { All patients } \\
n=31\end{array}$ & $\begin{array}{l}\text { Phase I } \\
n=9\end{array}$ & $\begin{array}{l}\text { Phase II } \\
n=22\end{array}$ \\
\hline \multicolumn{4}{|l|}{ Age, years } \\
\hline Median & 56 & 56 & 56 \\
\hline Range & $35-73$ & $44-73$ & $35-70$ \\
\hline \multicolumn{4}{|l|}{ Race } \\
\hline White & $27(87)$ & $8(89)$ & $19(86)$ \\
\hline African American & $4(13)$ & $1(11)$ & $3(14)$ \\
\hline \multicolumn{4}{|l|}{ ECOG performance status } \\
\hline 0 & $16(52)$ & $5(56)$ & $11(50)$ \\
\hline 1 & $12(39)$ & $4(44)$ & $8(36)$ \\
\hline 2 & $3(10)$ & $0(0)$ & $3(14)$ \\
\hline \multicolumn{4}{|l|}{ Menopausal status } \\
\hline Premenopausal & $1(3)$ & $0(0)$ & $1(5)$ \\
\hline Postmenopausal & $30(97)$ & $9(100)$ & $21(95)$ \\
\hline \multicolumn{4}{|l|}{ ER/PR/HER 2 neu status } \\
\hline $\mathrm{ER}+$ or $\mathrm{PR}+$ & $20(65)$ & $6(67)$ & $14(64)$ \\
\hline HER2 neu+ & $0(0)$ & $0(0)$ & $0(0)$ \\
\hline Triple negative & $11(35)$ & $3(33)$ & $8(36)$ \\
\hline \multicolumn{4}{|l|}{ No. of metastatic sites } \\
\hline 1 & $10(32)$ & $1(11)$ & $9(41)$ \\
\hline 2 & $12(39)$ & $5(56)$ & $7(32)$ \\
\hline 23 & $9(29)$ & $3(33)$ & $6(27)$ \\
\hline \multicolumn{4}{|l|}{ Sites of metastases } \\
\hline Liver & $15(48)$ & $3(33)$ & $12(55)$ \\
\hline Lung & $16(45)$ & $6(67)$ & $10(45)$ \\
\hline Bone & $17(55)$ & $6(67)$ & $11(50)$ \\
\hline \multicolumn{4}{|l|}{ Prior taxane therapy } \\
\hline Paclitaxel & $13(42)$ & $4(44)$ & $9(41)$ \\
\hline Docetaxel & $15(48)$ & $5(56)$ & $10(45)$ \\
\hline Nab-paclitaxel & $1(3)$ & $0(0)$ & $1(5)$ \\
\hline Paclitaxel and docetaxel & $2(6)$ & $0(0)$ & $2(9)$ \\
\hline \multicolumn{4}{|c|}{ Prior chemotherapy (metastatic setting) } \\
\hline 0 & $5(16)$ & $5(23)$ & $0(0)$ \\
\hline 1 & $14(45)$ & $10(45)$ & $4(44)$ \\
\hline 2 & $10(32)$ & $7(32)$ & $3(33)$ \\
\hline 3 & $2(6)$ & $0(0)$ & $2(22)$ \\
\hline
\end{tabular}

Cancer Chemother Pharmacol. Author manuscript; available in PMC 2013 July 01. 
Table 2

Toxicities $(n=31)$

\begin{tabular}{|c|c|c|c|}
\hline Adverse event & All grades & Grade 3 & Grade 4 \\
\hline \multicolumn{4}{|l|}{ Hematologic } \\
\hline Anemia & $17(55)$ & $0(0)$ & $0(0)$ \\
\hline Leukopenia & $14(45)$ & $3(10)$ & $2(6)$ \\
\hline Lymphopenia & $11(35)$ & $7(23)$ & $0(0)$ \\
\hline Neutropenia & $8(26)$ & $3(10)$ & $1(3)$ \\
\hline Febrile neutropenia & $1(3)$ & $0(0)$ & $0(0)$ \\
\hline Thrombocytopenia & $2(6)$ & $0(0)$ & $0(0)$ \\
\hline \multicolumn{4}{|l|}{ Non-hematologic } \\
\hline Arthralgias & $14(45)$ & $1(3)$ & $0(0)$ \\
\hline Myalgias & $14(45)$ & $0(0)$ & $0(0)$ \\
\hline Neuropathy motor & $5(16)$ & $1(3)$ & $0(0)$ \\
\hline Neuropathy sensory & $26(84)$ & $1(3)$ & $0(0)$ \\
\hline Anorexia & $15(48)$ & $2(6)$ & $0(0)$ \\
\hline Nausea & $17(55)$ & $0(0)$ & $0(0)$ \\
\hline Vomiting & $9(29)$ & $0(0)$ & $0(0)$ \\
\hline Diarrhea & $15(48)$ & $3(10)$ & $0(0)$ \\
\hline Dyspnea & $12(39)$ & $0(0)$ & $2(6)$ \\
\hline Fatigue & $30(97)$ & $6(19)$ & $0(0)$ \\
\hline Hypocalcemia & $2(6)$ & $0(0)$ & $0(0)$ \\
\hline Hypokalemia & $3(10)$ & $1(3)$ & $0(0)$ \\
\hline Hyponatremia & $2(6)$ & $1(3)$ & $0(0)$ \\
\hline Hypophosphatemia & $1(3)$ & $0(0)$ & $0(0)$ \\
\hline Infection without neutropenia & $12(39)$ & $2(6)$ & $0(0)$ \\
\hline Non-neutropenic fever & $7(23)$ & $0(0)$ & $0(0)$ \\
\hline Rash & $16(52)$ & $0(0)$ & $0(0)$ \\
\hline Renal insufficiency & $5(16)$ & $0(0)$ & $1(3)$ \\
\hline Thrombosis & $2(6)$ & $0(0)$ & $1(3)$ \\
\hline
\end{tabular}

There was 1 patient with grade 5 acute respiratory distress (ARDS) within 30 days of study termination 


\section{Table 3}

Phase II antitumor activity

\begin{tabular}{ll}
\hline Antitumor activity, $\boldsymbol{n}(\boldsymbol{\%})$ & $\begin{array}{l}\text { Phase II } \\
\boldsymbol{N}=\mathbf{2 2}\end{array}$ \\
\hline Complete response & $0(0)$ \\
Partial response & $5(23)$ \\
Stable disease & $9(41)$ \\
Progressive disease & $8(36)$ \\
Objective response rate & $5(23,95 \%$ CI $8-45)$ \\
Median PFS, months & 3.4 \\
$95 \%$ CI & $2.1-4.9$ \\
Median OS, months & 11.2 \\
$95 \%$ CI & $6.6-16.0$ \\
\hline
\end{tabular}

$P F S$ progress-free survival, $O S$ overall survival, $C I$ confidence interval 
